\title{
Contribution of Residual Stress to the Strength of Abrasive Ground Alumina
}

\author{
W. H. Tuan* and J. C. Kuo \\ Institute of Materials Science and Engineering, National Taiwan University, Taipei, 10764, Taiwan, \\ Republic of China
}

(Received 14 July 1998; accepted 16 October 1998)

\begin{abstract}
Residual stresses are introduced into the surface region of ceramics during abrasive grinding. The presence of the residual stresses can affect the strength of the ground specimens. In the present study, a methodology is proposed to determine the contribution of the residual stresses to the strength of the ground specimens. The method uses Weibull statistics to evaluate the crack size distribution before and after annealing. If the crack size distribution is not changed after annealing, the amount of the strength reduction is attributed to the effect of residual stresses as verified by direct measurements of the residual stress at the surface. (C) 1999 Elsevier Science Limited. All rights reserved
\end{abstract}

Keywords: residual stresses, finishing, surfaces, strength, $\mathrm{Al}_{2} \mathrm{O}_{3}$,

\section{Introduction}

Dimensional tolerance has to be tightly controlled for many structural applications. Abrasive grinding is therefore frequently used to meet the requirement. During abrasive grinding, material together with the flaws in the surface region are removed, while residual stresses are introduced into the newly formed surface region. The magnitude of the residual stress has been determined by a $\mathrm{X}$-ray topography technique on diamond, ${ }^{1}$ a photoelastic technique on $\mathrm{MgO},{ }^{2}$ an indentation technique on a glass-ceramic ${ }^{3}$ and $\mathrm{Si}_{3} \mathrm{~N}_{4},{ }^{4}$ an $\mathrm{X}$-ray diffraction technique on $\mathrm{Al}_{2} \mathrm{O}_{3},{ }^{5}$ and a bending technique on many ceramics. ${ }^{6}$ Typically, these techniques only reveal the residual stress in a shallow surface region. For example, a compressive

*To whom correspondence should be addressed. Fax: +886 223634562; e-mail: tuan@ccms.ntu.edu.tw stress of $350 \mathrm{MPa}$ was detected in the $10 \mu \mathrm{m}$ surface region of $\mathrm{Si}_{3} \mathrm{~N}_{4} \cdot{ }^{6}$

The magnitude of the residual stress in a deeper surface region can also be detected by modifying the previous techniques. For example, the surface region can be removed by polishing to expose the region beneath the surface. ${ }^{6}$ The distribution of the residual stress as a function of depth can then be determined. However, this technique can lead to biased results, mainly because the polishing technique can also induce residual stress in the surface region. ${ }^{6,7}$ Other techniques such as neutron diffraction and acoustic scattering which have deeper penetration depth than that of $\mathrm{X}$-rays were used to determine the residual stress profile in $\mathrm{SiC}-\mathrm{Al}_{2} \mathrm{O}_{3}$ composites ${ }^{8}$ and $\mathrm{Si}_{3} \mathrm{~N}_{4}{ }^{4}$

The distribution of the residual stress beneath the surface after abrasive grinding has therefore been established. The residual stress is compressive on the surface and tensile underneath. ${ }^{4}$ However, the reported values of the residual stress differ significantly from one report to another. The variation may be due to the strong dependence of the magnitude of the residual stress on the grinding conditions. For example, the residual stress induced in a $\mathrm{Si}_{3} \mathrm{~N}_{4}$ and a ferrite by a dressed diamond wheel is twice that induced by an undressed wheel. ${ }^{6}$ The contribution of the residual stress to the resulting strength of the ground specimens is also unclear. For example, one report stated that the strength of a $\mathrm{Si}_{3} \mathrm{~N}_{4}$ is not changed despite a compressive surface stress as high as $350 \mathrm{MPa}{ }^{6}$ However, another report claimed that the strength of a machined $\mathrm{Si}_{3} \mathrm{~N}_{4}$ specimen was nearly twice that of the polished one. ${ }^{4}$

There is not only residual stress introduced into the newly exposed surface region, but machining flaws are also formed. ${ }^{4,9,10}$ The size of the machining flaws depends strongly on the microstructure of the machined specimens. However, many processing flaws exist in the ceramic components before 
the components are ground. The residual stresses can be reduced by an annealing treatment. ${ }^{9}$ However, the size of flaws may also change during annealing. The contribution from residual stresses to the strength is therefore difficult to be quantified by annealing treatment alone. ${ }^{11}$ In the present study, the magnitude of residual stress in the ground specimens is manipulated by using an annealing treatment. In addition, the crack size distribution is monitored by using Weibull statistics. The contribution of residual stress to strength is determined by combining the annealing treatment and Weibull statistics.

\section{Experimental}

A commercial alumina powder ( $\mathrm{CH}-92 \mathrm{~A}, 92 \%$ $\mathrm{Al}_{2} \mathrm{O}_{3}$, Marusu Co., Japan) was used in the present study. The specimens were prepared by die-pressing the powder into rectangular bars. The pressing pressure employed was $140 \mathrm{MPa}$. The powder compacts were sintered at $1480^{\circ} \mathrm{C}$ for $1 \mathrm{~h}$. After sintering, the size of the rectangular bars is $3.2 \times 4.0 \times 44 \mathrm{~mm}$.

Grinding was performed using a surface grinder with a resin bonded 325 grit diamond wheel. The diameter of the wheel was $175 \mathrm{~mm}$. Truing and dressing of the diamond wheel had a dramatic effect on the grinding quality. ${ }^{6,12}$ The wheel was first trued by grinding a low carbon steel and then dressed with a porous alumina dressing stick before grinding the specimens. A water-based oil emulsion grinding fluid was used for cooling. The specimens were ground longitudinally at a table speed of $0.17 \mathrm{~m} / \mathrm{s}$ and a wheel surface speed of $27.5 \mathrm{~m} / \mathrm{s}$. The depth of cut was $10 \mu \mathrm{m} /$ pass. Only the tensile surface of the flexural specimens was ground. The depth of cut was kept constant until $200 \mu \mathrm{m}$ in thickness of the specimen was removed. The specimens were not beveled.

Some specimens were annealed to remove the residual stresses. These specimens were first ground at $10 \mu \mathrm{m} /$ pass to remove a thickness of $200 \mu \mathrm{m}$. The specimens were then annealed at $1190^{\circ} \mathrm{C}$ for 1 or $10 \mathrm{~h}$. The extent of residual stresses in surface region was quantified by the X-ray diffraction (XRD) method $(30 \mathrm{KV}, 20 \mathrm{~mA})$. A thin layer of silicon slurry was first coated on the surface of the XRD specimens. The silicon layer was used as an internal standard to determine the shift of $2 \theta$ of the (110) peak of $\mathrm{Al}_{2} \mathrm{O}_{3}$. The final density was determined by the water displacement method. The grain boundaries were revealed by thermal etching the polished specimens. The microstructure was observed with scanning electron microscopy (SEM). The grain size was determined using the line intercept technique, with more than 300 grains counted. Four-point bending was used to determine the flexural strength of the specimens. The four-point span was $10 \mathrm{~mm} \times 30 \mathrm{~mm}$. The rate of loading was $0.083 \mathrm{~mm} / \mathrm{s}$. The surface roughness of the ground specimens was measured with a stylus surface profilometer.

\section{Results and Discussion}

The absolute density of the alumina specimens is $3.65 \mathrm{~g} / \mathrm{cm}^{3}$. The density is lower than the theoretical density for pure $\mathrm{Al}_{2} \mathrm{O}_{3}$, indicating the presence of a glassy phase in the specimens. The microstructure of the specimen is shown in Fig. 1. The average size of $\mathrm{Al}_{2} \mathrm{O}_{3}$ grains is $1.7 \mu \mathrm{m}$. From microstructural observation, the porosity in the specimen is less than $2 \%$. The ground surface of the specimen is shown in Fig. 2. Many grains have pulled out and a small amount of smooth area is observed on the surface. Despite the presence of a glassy phase, the microstructural features of the specimens after grinding are very similar to those of high-purity alumina specimens. ${ }^{10}$ The material removal mechanism is suggested as grain disintegration resulting from intergranular microfractures.

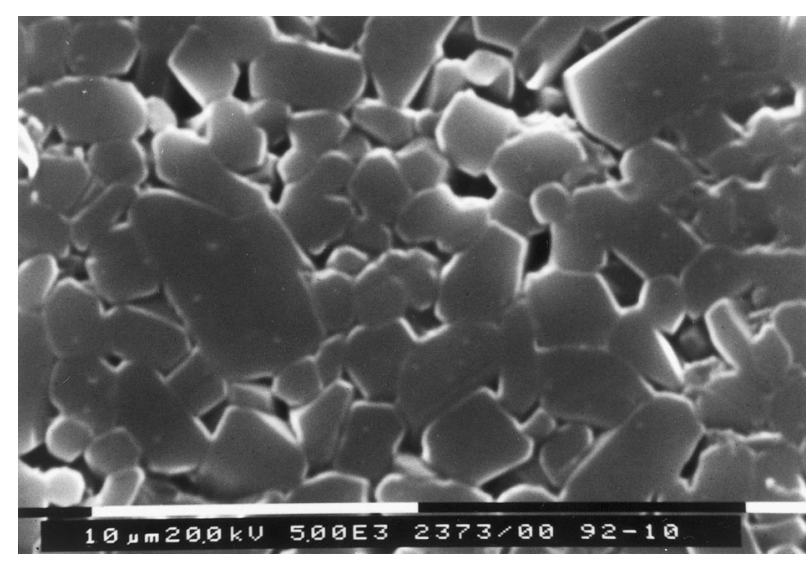

Fig. 1. The microstructure of the alumina specimen.

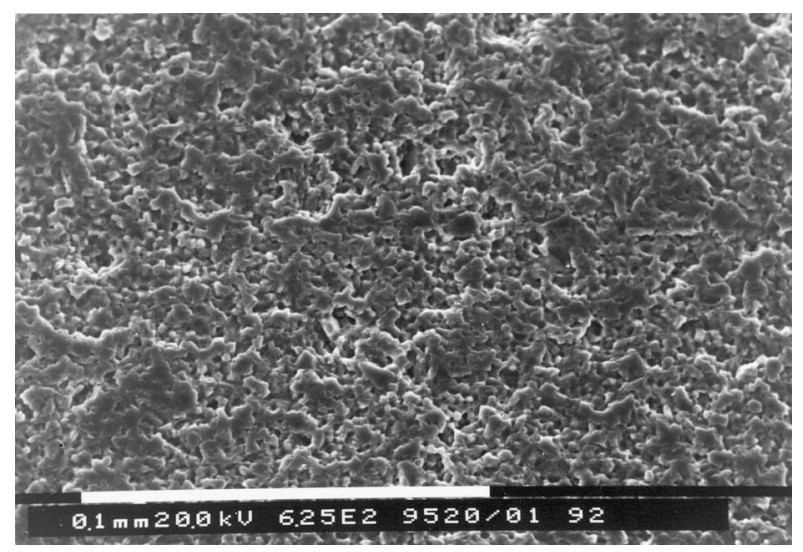

Fig. 2. The surface of the ground specimen. 
The average surface roughness, $R_{a}$, and the maximum roughness, $R_{\max }$, of the ground specimens are $0.26 \mu \mathrm{m}$ and $5.8 \mu \mathrm{m}$, respectively.

The average strength of the specimens is shown in Table 1. The strength of the as-sintered specimens is increased by $92 \mathrm{MPa}$ after abrasive grinding. As the ground specimens are annealed at $1190^{\circ} \mathrm{C}$ for $1 \mathrm{~h}$, the strength decreased by $40 \mathrm{MPa}$. By increasing the annealing time from 1 to $10 \mathrm{~h}$, the strength is decreased slightly by $13 \mathrm{MPa}$.

The variation of strength can be characterized with Weibull statistics. The Weibull statistics treats the probability of failure, F, based on a weakestlink theory as ${ }^{13}$

$$
F=1-\exp \left[-\left(\frac{\sigma-\sigma_{u}}{\sigma_{o}}\right)^{m} V\right]
$$

where $\sigma$ is the strength of the specimen, $\sigma_{u}$ the threshold strength below which fracture can not occur, $\sigma_{o}$ the characteristic strength which corresponds to $63 \cdot 2 \%$ probability of failure, $m$ the Weibull modulus and $V$ the stressed volume. Equation (1) can be re-arranged as follows,

$\ln \{\ln [1 /(1-F)]\}=m \ln \left(\sigma-\sigma_{u}\right)-m \ln \sigma_{o}+$ constant

The above equation has been frequently termed as the 3-parameter Weibull equation. The probability of failure, $F$, is calculated as

$$
F=(n-0 \cdot 5) / N
$$

where $n$ is the $n$th specimen as the experimental data are ranked in order, $N$ the total number of the specimens.

When the threshold strength, $\sigma_{u}$, is assumed as zero, eqn (2) simplifies as

$$
\ln \{\ln [1 /(1-F)]\}=m \ln \sigma-m \ln \sigma_{o}+\text { constant }
$$

Table 1. The number of specimens used, strength and Weibull modulus of the as-sintered, ground and annealed specimens.

\begin{tabular}{lcccc}
\hline & As-sintered & $\begin{array}{r}\text { Ground } \\
\text { Annealed, } \\
119^{\circ} \mathrm{C} / \mathrm{h} h\end{array}$ & $\begin{array}{c}\text { Annealed, } \\
119^{\circ} \mathrm{C} / 10 \mathrm{~h}\end{array}$ \\
\hline $\begin{array}{l}\text { Number of } \\
\text { specimens used }\end{array}$ & 30 & 30 & 29 & 29 \\
$\begin{array}{l}\text { Average } \\
\text { strength/MPa }\end{array}$ & 199 & 291 & 251 & 238 \\
$\begin{array}{l}\text { Standard } \\
\text { deviation of } \\
\text { strength }\end{array}$ & 41 & 21 & 17 & 23 \\
$\begin{array}{l}\text { 2-parameter } \\
\text { Weibull } \\
\text { modulus }\end{array}$ & 5.6 & $16 \cdot 6$ & $18 \cdot 1$ & 12.4 \\
$\begin{array}{l}\text { 3-parameter } \\
\text { Weibull } \\
\text { modulus }\end{array}$ & 1.3 & 2.4 & 2.3 & 1.5 \\
\hline
\end{tabular}

The above equation is termed as the 2-parameter Weibull equation. Using both the 2-parameter and 3 -parameter statistics to evaluate the data can shed more light on the data distribution. ${ }^{14}$ The value of Weibull modulus is determined by least-square regression analysis. The 2-parameter Weibull distribution for the as-sintered, ground and annealed specimens is shown in Fig. 3. The figure suggests that the threshold strength, $\sigma_{u}$, is not zero. By using the regression fit to determine the value of $\sigma_{u}$, the 3-parameter Weibull distribution can be determined. The 2-parameter Weibull distribution and 3-parameter Weibull distribution for the as-sintered specimens are shown in Fig. 4. The correlation factor for the 2-parameter and 3-parameter equations is 0.96 and 0.97 , respectively. Both equations give reasonably good fit to the data. The values of the Weibull modulus determined by the Weibull 2-parameter and 3-parameter equations are shown in Table 1 . The values of the Weibull modulus calculated by the 2-parameter and 3parameter equations given in Table 1 show a similar trend; the two analyses are consistent to each other.

The grain size of the annealed specimens was measured and no significant grain growth after

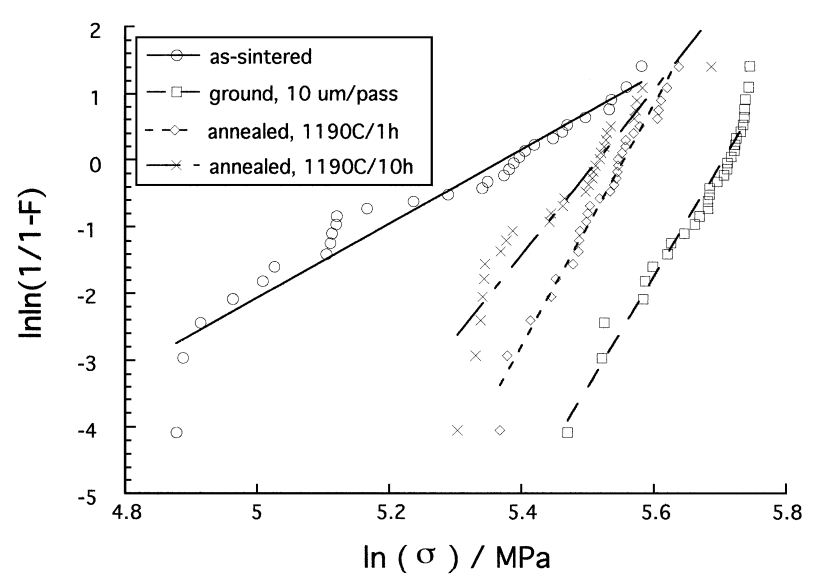

Fig. 3. Weibull plots calculated using the 2-parameter statistics.

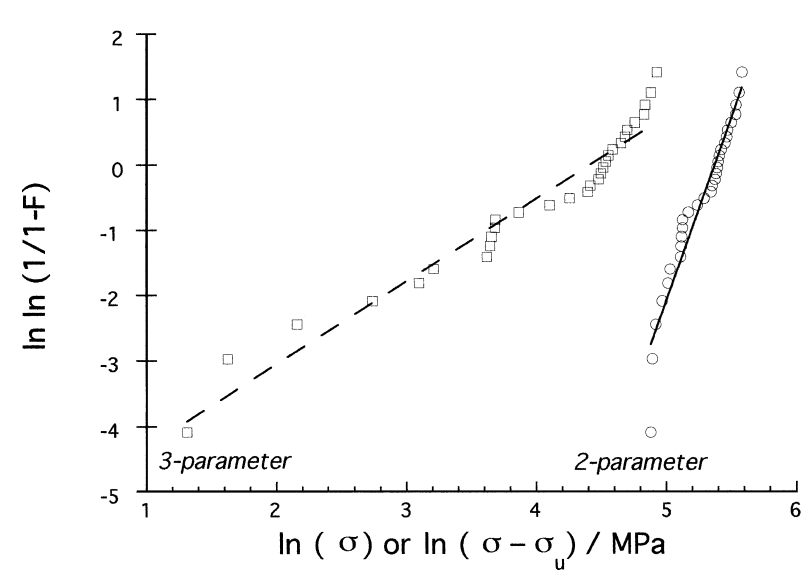

Fig. 4. Comparison of the 2-parameter and 3-parameter Weibull distribution for the as-sintered specimens. 
annealing was noted. However, the size of cracks may be modified during annealing through crack opening ${ }^{15}$ or crack healing. ${ }^{16,17}$ Previous study suggested that the size of cracks in alumina can be altered by heat treating at a temperature as low as $1100^{\circ} \mathrm{C} .{ }^{17}$ The change in strength after annealing which should therefore result from either a change in the critical crack size or a reduction in the residual stress. To evaluate the contribution of residual stress to strength, the change of crack size distribution is monitored by using the Weibull statistics (Fig. 3 and Table 1).

From Table 1, the Weibull modulus increases significantly after abrasive grinding and is then virtually unchanged as the specimens are annealed at $1190^{\circ} \mathrm{C}$ for $1 \mathrm{~h}$. This indicates that the crack size distribution is not altered by annealing at $1190^{\circ} \mathrm{C}$ for $1 \mathrm{~h}$. The Weibull modulus decreases as the annealing time is increased to $10 \mathrm{~h}$, which indicates that the size of cracks is modified by the $10 \mathrm{~h}$ anneal. The strength reduction after $1 \mathrm{~h}$ annealing $(40 \mathrm{MPa})$ can be attributed to the release of residual stress, for the crack size is not changed after annealing at $1190^{\circ} \mathrm{C}$ for $1 \mathrm{~h}$. This can be further confirmed by the XRD analysis. The shift of diffraction angle, $\Delta 2 \theta$, of ground specimens is 0.052 . This value is decreased to 0.005 after annealing at $1190^{\circ} \mathrm{C}$ for $1 \mathrm{~h}$, indicating that most residual stresses are relieved after annealing.

The surface residual stress after abrasive grinding can be much higher than $40 \mathrm{MPa} .{ }^{6}$ However, the strength of brittle ceramics is controlled by the stress acting on the critical crack. The residual stress that surrounds the tip of critical crack is different from the surface stress. However, the size of the critical crack varies from one specimen to another. Therefore, direct measurement of the residual stress can shed little light on the contribution of residual stress to strength. In the present study, it is not intended to indicate that a residual stress of $40 \mathrm{MPa}$ existed at a certain depth from the surface. However, it demonstrates that the methodology of using both the annealing treatment and Weibull statistics can determine the contribution of residual stress to strength.

The strength increased by $92 \mathrm{MPa}$ after abrasive grinding. Since there is a $40 \mathrm{MPa}$ contribution from the residual stress, the additional $50 \mathrm{MPa}$ must arise from the removal of large cracks by grinding. These assumptions can be verified with Weibull statistics (Fig. 5). The Weibull modulus of the as-sintered specimens increased significantly after abrasive grinding, which removed the material from the surface region. The depth of the materials removed in the present study is about $200 \mu \mathrm{m}$, which is likely larger than the size of flaws produced during the processing stages. Due to the

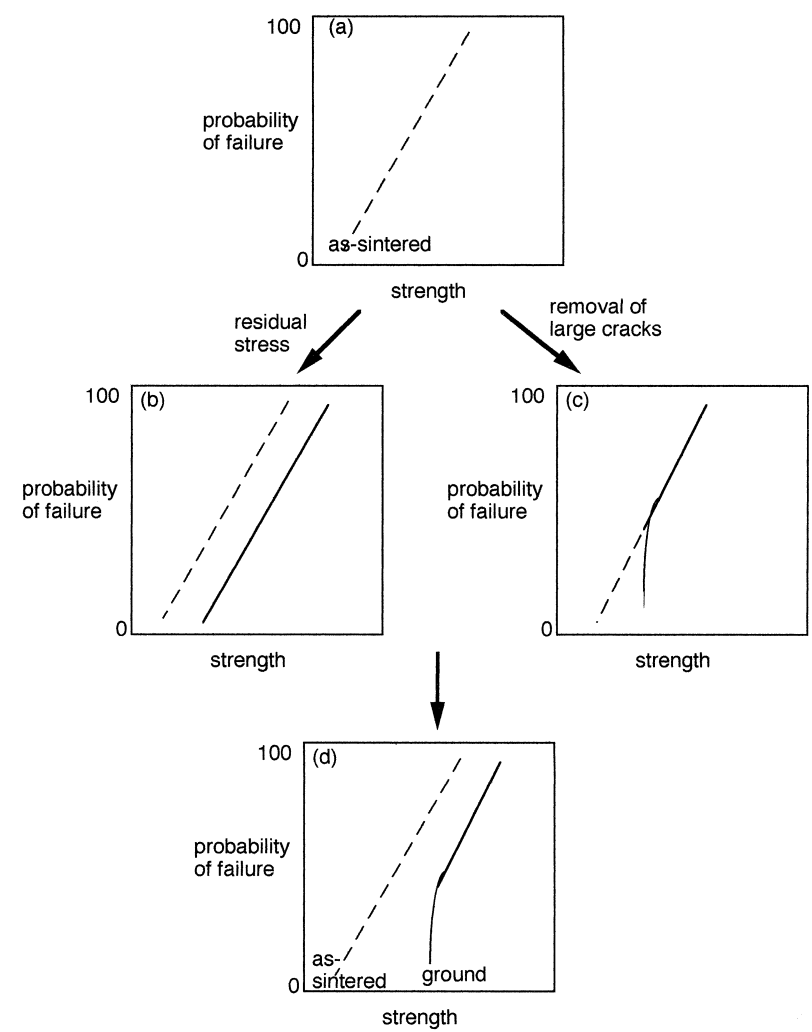

Fig. 5. (a) The strength distribution of the as-sintered specimens. (b) The Weibull distribution of the as-sintered specimens is shifted to its right by introducing residual stress. (c) The large cracks in surface region are removed by grinding. (d) The strength and Weibull modulus of the ground specimens is therefore much higher than those of the as-sintered specimens.

average strength increase, the large cracks in surface region must be either removed or reduced in size and further indicates that large cracks tend to form in the surface region of the specimens used in the present study during powder processing and firing. Due to the presence of residual stress and removal of large cracks, the Weibull modulus is significantly enhanced (Fig. 5).

A recent study suggested that the strength of the alumina specimens with high purity ( $>99 \% \mathrm{Al}_{2} \mathrm{O}_{3}$ ) was increased by $40 \mathrm{MPa}$ after abrasive grinding. ${ }^{10}$ A $30 \mathrm{MPa}$ strength increase is attributed to the introduction of residual stress during grinding. This value is close to the strength increase for the present system. It implies that the residual stress induced by grinding is mainly stored in the alumina phase. The contribution of the removal of large crack from the surface region for the present system is as large as $50 \mathrm{MPa}$. It suggests that large cracks are likely formed in the impure system during processing. The removal of the surface region can thus enhance the strength significantly.

\section{Conclusions}

In the present study, alumina was used to investigate the contribution of residual stress induced 
during abrasive grinding on strength. The strength of the as-sintered specimens is increased by $92 \mathrm{MPa}$ by abrasive grinding. The strength of the ground specimens is reduced by $40 \mathrm{MPa}$ as a suitable annealing profile is applied. The annealing treatment can easily reduce the residual stress and can also change the size of cracks. By employing the Weibull 2-parameter and 3-parameter statistics, the crack size after annealing at $1190^{\circ} \mathrm{C}$ for $1 \mathrm{~h}$ is found unchanged, whereas XRD analysis reveals little residual stress in the surface region of the annealed specimens. The strength reduction after annealing results primarily from the removal of residual stress. The contribution of residual stress to the strength after grinding can thus be determined.

The present study demonstrates that abrasive grinding influences the strength of machined ceramics in two ways. One feature is that the grinding introduces residual stresses into the surface region. The presence of the residual stresses is compressive and hence beneficial to the strength. Another feature is that large cracks are frequently formed in the surface region during processing. These large cracks can be removed or reduced in size by a suitable grinding process. Therefore, both the magnitude and variation in strength can be significantly improved by applying abrasive grinding.

\section{Acknowledgements}

The present study was supported by the National Science Council, Republic of China, through contract number NSC86-2216-E002-031.

\section{References}

1. Frank, F. C., Lawn, B. R. and Lang, A. R., A study of strains in abraded diamond surfaces. Proc. R. Soc. London, Ser. A., 1967, 310, 239-252.
2. Bernal, E. and Koepke, B. G., Residual stresses in machined MgO crystals. J. Am. Ceram. Soc., 1973, 56, 634-639.

3. Cook, R. F., Lawn, B. R., Dabbs, T. P. and Chantikul, P., Effect of machining damage on the strength of a glass ceramic. J. Am. Ceram. Soc., 1981, 64, c121-c122.

4. Marshall, D. B., Evans, A. G., Khuri-Yakub, B. T., Tien, J. W. and Kino, G. S., The nature of machining damage in brittle materials. Proc. R. Soc. London, Ser. A, 1983, 385, 461-475.

5. Lange, F. F., James, M. R. and Green, D. J., Determination of residual surface stresses caused by grinding in polycrystalline $\mathrm{Al}_{2} \mathrm{O}_{3}$. J. Am. Ceram. Soc., 1983, 66, c16-c17.

6. Johnson-Walls, D., Evans, A. G., Marshall, D. B. and James, M. R., Residual stresses in machined ceramics. $J$. Am. Ceram. Soc., 1986, 69, 44-47.

7. Hockey, B. J., Plastic deformation on aluminum oxide by indentation and abrasion. J. Am. Ceram. Soc., 1971, 54, 223-231.

8. Majumdar, S., Kupperman, D. and Singh, J., Determination of residual stresses in a $\mathrm{SiC}-\mathrm{Al}_{2} \mathrm{O}_{3}$ composite using neutron diffraction. J. Am. Ceram. Soc., 1988, 71, 858863.

9. Matsuo, Y., Ogasawara, T., Kimura, S., Sato, S. and Yasuda, E., The effect of annealing on surface machining damage of alumina ceramics. J. Ceram. Soc. Jpn, Int. Ed., 1991, 99, 371-376.

10. Tuan, W. H. and Kuo, J. C., Effect of abrasive grinding on the strength and reliability of alumina. J. Euro. Ceram. Soc., 1998, 18, 799-806.

11. Samuel, S., Chandrasekar, S., Farris, T. N. and Licht, R. H., Effect of residual stresses on the fracture of ground ceramics. J. Am. Ceram. Soc., 1986, 72, 1960-1966.

12. Tuan, W. H. and Kuo, J. C., Effect of truing of diamond wheel on the strength of alumina after abrasive grinding. J. Mater. Sci. Letter, 1997, 16, 806-808.

13. Weibull, W., A statistical distribution function of wide applicability. J. Appl. Mech., 1951, 18, 293-297.

14. Quirmbach, P., Wolf, M., Brook, R. J. and Hennicke, H. W., Development of microstructure during pressureless sintering of alumina. J. European Ceram. Soc., 1992, 10, $51-57$.

15. Thompson, A. M., Chan, H. M. and Harmer, M. P., Crack healing and stress relaxation in $\mathrm{Al}_{2} \mathrm{O}_{3} . J . A m$. Ceram. Soc., 1995, 78, 567-571.

16. Lange, F. F. and Radford, K. C., Healing of surface cracks in polycrystalline $\mathrm{Al}_{2} \mathrm{O}_{3}$. J. Am. Ceram. Soc., 1970, 53, 420-421.

17. Moffatt, J. E., Plumbridge, W. J. and Hermann, R., High temperature crack annealing effects on fracture toughness of alumina and alumina-SiC composite. Brit. Ceram.Trans., 1996, 95, 23-29. 